\title{
Ethanolic Extract of Cockroach Wing Powder as Corrosion Inhibitor for N80 Steel in an ASTM D1141-98(2013) Standard Artificial Seawater Solution
}

\author{
Shivani Singh ${ }^{1}$, Rahul Singh ${ }^{1, *}$, Neeta Raj Sharma ${ }^{1, *}$, Ambrish Singh ${ }^{2, *}$ \\ ${ }^{1}$ School of Bioengineering and Biosciences, Lovely Professional University, Phagwara, Punjab, India- \\ 144402. \\ ${ }^{2}$ School of New Energy and Materials, Southwest Petroleum University, Chengdu-610500, Sichuan, \\ China. \\ *E-mail: neeta.raj@1pu.co.in; rahul.16188@1pu.co.in; vishisingh4uall@gmail.com
}

doi: $10.20964 / 2021.08 .43$

Received: 6 May 2021 / Accepted: 4 June 2021 / Published: 30 June 2021

\begin{abstract}
Electrochemical, localized electrochemical and surface exploration procedures were used to investigate the potential of wings plucked from adult cockroaches (WAC) to attenuate N80 steel corrosion in simulated saltwater. According to the impedance studies, a maximum inhibition efficacy of $96.8 \%$ was recorded with $400 \mathrm{mg} / \mathrm{L}$ of WAC inhibitor in corrosive environments. This was owing to the steel's increased resistance as the compounds from WAC extract effectively occluded the corrosion centers. With 94 percent efficiency in the corrosive solution, electrochemical frequency modulation (EFM), a novel and prominent technology, also revealed that WAC has high mitigation ability. On the N80 steel, the polarization data revealed a cathodic preponderance of WAC inhibitor. To control localized corrosion, researchers used scanning electrochemical microscopy (SECM) and scanning Kelvin probe (SKP) techniques. The WAC film development is shown using scanning electron microscopy (SEM).
\end{abstract}

Keywords: N80 steel; Cockroach wings; Corrosion; SKP

\section{$\underline{\text { FULL TEXT }}$}

(C) 2021 The Authors. Published by ESG (www.electrochemsci.org). This article is an open access article distributed under the terms and conditions of the Creative Commons Attribution license (http://creativecommons.org/licenses/by/4.0/). 